\title{
Rapid sequence evolution is associated with genetic incompatibilities in the plastid CIp complex
}

\author{
Salah E. Abdel-Ghany ${ }^{1, *}$, Lisa M. LaManna ${ }^{2}$, Zora Svab², Haleakala T. Harroun ${ }^{1}$, Pal Maliga ${ }^{2,3}$, \\ Daniel B. Sloan ${ }^{1, *}$ \\ ${ }^{1}$ Department of Biology, Colorado State University, Fort Collins, CO 80523, USA \\ ${ }^{2}$ Waksman Institute of Microbiology, Rutgers University, Piscataway, NJ 08854, USA \\ ${ }^{3}$ Department of Plant Biology, Rutgers University, New Brunswick, NJ 08901, USA \\ *Correspondence: salah.abdel-ghany@colostate.edu, dan.sloan@colostate.edu
}

\begin{abstract}
1 The plastid caseinolytic protease (Clp) complex plays essential roles in maintaining protein

2 homeostasis and comprises both plastid-encoded and nuclear-encoded subunits. Despite the Clp

3 complex being retained across green plants with highly conserved protein sequences in most

4 species, examples of extremely accelerated amino acid substitution rates have been identified in

5 numerous angiosperms. The causes of these accelerations have been the subject of extensive

6 speculation but still remain unclear. To distinguish among prevailing hypotheses and begin to

7 understand the functional consequences of rapid sequence divergence in Clp subunits, we used

8 plastome transformation to replace the native clpP1 gene in tobacco (Nicotiana tabacum) with

9 counterparts from another angiosperm genus (Silene) that exhibits a wide range in rates of Clp

10 protein sequence evolution. We found that antibiotic-mediated selection could drive a transgenic

11 clpP1 replacement from a slowly evolving donor species ( $S$. latifolia) to homoplasmy but that clpP1

12 copies from Silene species with accelerated evolutionary rates remained heteroplasmic, meaning

13 that they could not functionally replace the essential tobacco $c / p P 1$ gene. These results suggest that

14 observed cases of rapid Clp sequence evolution are a source of epistatic incompatibilities that must

15 be ameliorated by coevolutionary responses between plastid and nuclear subunits.
\end{abstract}

16

17 Keywords: $c / p P$, cytonuclear coevolution, epistasis, Nicotiana, plastome editing, Silene 


\section{INTRODUCTION}

Owing to the endosymbiotic origins of mitochondria and plastids (chloroplasts) and the subsequent history of cytonuclear integration in eukaryotes, many of the key enzyme complexes in these organelles are assembled from a mix of subunits encoded in both nuclear and cytoplasmic genomes (Rand, et al. 2004; Gould, et al. 2008; Gray 2012; Roger, et al. 2017; Sloan, et al. 2018). As such, core eukaryotic functions require coordinated regulation and coevolution between genomes that differ in nearly every respect, including their modes of transmission, mutation rates, copy numbers, and mechanisms of replication and expression.

The plastid caseinolytic protease ( $\mathrm{Clp})$ is one example of a cytonuclear enzyme complex. In the model angiosperm Arabidopsis thaliana, the proteolytic core of this complex consists of 14 subunits in two heptameric rings encoded by nine different genes, including eight nuclear loci and a single gene (clpP1) in the plastid genome (plastome). The complete Clp complex also contains a number of associated chaperones and adapters that are all nuclear-encoded (Nishimura, et al. 2015; Nishimura and van Wijk 2015). The clpP1 gene appears to be essential based on studies that have modified the plastome to knockout this gene in the angiosperm Nicotiana tabacum (Shikanai, et al. 2001; Kuroda and Maliga 2003) and the green alga Chlamydomonas reinhardtii (Huang, et al. 1994). Likewise, disruption of nuclear genes that encode core Clp subunits also produces severe phenotypic effects (Sjögren, et al. 2006; Zheng, et al. 2006; Koussevitzky, et al. 2007; Kim, et al. 2009; Kim, et al. 2013; Moreno, et al. 2017). The Clp complex plays a central role in protein quality control and homeostasis in plastids, and many potential proteolytic targets have now been identified (Majeran, et al. 2000; Nishimura, et al. 2013; Tapken, et al. 2015; Apitz, et al. 2016; Pulido, et al. 2016; Moreno, et al. 2018; Welsch, et al. 2018; Wu, et al. 2018; Montandon, et al. 2019).

In accordance with the key functions of the Clp complex, the clpP1 gene is almost universally retained in the plastomes of green plants and is highly conserved in sequence in most species (Williams, et al. 2019). For example, angiosperm ClpP1 protein sequences often share $\sim 60 \%$ amino acid identity with their counterparts in cyanobacteria despite more than a billion years of evolutionary divergence. However, a number of independent angiosperm lineages exhibit massive increases in rates of protein sequence divergence in this protein (Erixon and Oxelman 2008; Williams, et al. 2019). In extreme cases, ClpP1 sequences have been found to retain less than $35 \%$ amino acid identity even between closely related species in the same genus (Rockenbach, et al. 2016). The level of sequence divergence can be so extensive that the $c / p P 1$ gene is often overlooked in plastome annotations (Haberle, et al. 2008; Straub, et al. 2011; Fajardo, et al. 2013; Yao, et al.

51 2015) or predicted to be a nonfunctional pseudogene (Hirao, et al. 2008; Zhang, et al. 2014).

52 However, in the limited number of cases that have been investigated to date, these highly divergent

53 clpP1 gene copies appear to be functional, with evidence of transcription and proper splicing 
54 (Williams, et al. 2015) or even translation and likely assembly into the core Clp complex (Williams, et al. 2019). Although the relative contributions of mutation and selection to these changes in rates of $c / p P 1$ evolution remain unclear, there is evidence that the gene may be subject to extensive positive selection for amino-acid substitutions in some species (Erixon and Oxelman 2008).

In angiosperms with highly divergent copies of $c / p P 1$, there are also correlated increases in the rate of protein sequence evolution in nuclear-encoded Clp subunits (Williams, et al. 2019; Forsythe, et al. 2021) and signatures of positive selection on these nuclear genes based on both population genetic and phylogenetic data (Rockenbach, et al. 2016). The apparent action of positive selection on interacting proteins encoded in two different genomes is reminiscent of antagonistic molecular coevolution that can occur between hosts and pathogens (Hughes and Nei 1988; Aguileta, et al. 2009). As such, it has been hypothesized that the examples of extreme protein sequence divergence in the Clp complex could be driven by selfish plastid-nuclear interactions (Rockenbach, et al. 2016). Although the origins of mitochondria and plastids represent some of the most intimate and important mutualisms in the history of life, they can still be involved in antagonistic interactions with the nucleus, including selfish over-replication within cells and conflict over allocation to female vs. male reproduction (Havird, et al. 2019). Although these types of conflicts have been more extensively documented in mitochondria, plastids may also be involved in selfish interactions with the nucleus. For example, the proliferation of genetically incompatible plastids within

72 heteroplasmic Oenothera lines has been associated with variation in plastid-encoded components of 73 fatty acid biosynthesis pathways and intracellular competition (Sobanski, et al. 2019). Plastid-nuclear 74 incompatibilities have also been implicated in male sterility (Bogdanova, et al. 2015; Nováková, et al. 2019), which is a classic source of cytonuclear conflict (Touzet and Budar 2004; Fujii, et al. 2011).

Alternatively, positive selection could be indicative of some combination of adaptation, mutation accumulation, and compensatory coevolution rather than an antagonistic interaction. For example, in some systems, cytoplasmic genomes may accumulate disruptive sequence changes that require compensatory changes in nuclear genes to maintain function (Osada and Akashi 2012; Sloan, et al. 2017). Generation of "mismatched" combinations of plastid and nuclear genotypes through crossing designs or protoplast fusion have often identified plastid-nuclear incompatibilities

82 (Greiner, et al. 2011; Barnard-Kubow, et al. 2016), and in rare cases those incompatibilities have 83 been traced to specific loci (Schmitz-Linneweber, et al. 2005; Bogdanova, et al. 2015; Zupok, et al.

84 2020). A more targeted approach to probing plastid-nuclear incompatibilities involves genome 85 editing to manipulate or replace individual genes. For example, plastome transformation in tobacco

86 (N. tabacum) to replace its copy of $r b c L$ with the orthologous sequence from sunflower (Helianthus 87 annuus) successfully generated a hybrid tobacco-sunflower Rubisco complex, which contains plastid-encoded RbcL subunits and nuclear-encoded RbcS subunits (Kanevski, et al. 1999). 
Although catalytically active, this hybrid complex exhibited reduced function and evidence of incompatibilities between $\mathrm{RbcL}$ and $\mathrm{RbcS}$ subunits derived from different angiosperm lineages.

Here, we apply a plastome editing approach to replace tobacco $c / p P 1$ with copies from other angiosperms with highly divergent rates of clpP1 sequence evolution. For donor species, we take advantage of the extreme rate variation within the angiosperm genus Silene (Caryophyllaceae). Some species within this genus, including $S$. latifolia, have retained the typically low rates of ClpP1 protein sequence evolution found in most angiosperms, whereas others such as S. conica and S. noctiflora exhibit massive rate accelerations (Erixon and Oxelman 2008; Sloan, Triant, Forrester, et al. 2014; Rockenbach, et al. 2016). These Silene species are separated from tobacco by the same amount of divergence in time but differ radically in levels of ClpP1 protein sequence divergence (Figure 1). If the high levels of CIpP1 divergence in species such as S. conica and S. noctiflora reflect the role of this protein in some type of selfish plastid phenotype, introducing their gene sequences into tobacco would be akin to exposing a naïve host to a pathogen. Under this model, we would predict that these transgenic genotypes would exhibit signs of selfish conflict such as overreplication of the plastome within cells or induction of male sterility phenotypes. On the other hand, if the rapid sequence changes in Clp subunits solely reflect mutualistic cytonuclear coevolution to maintain compatibility, then increasing levels of sequence divergence should be associated with greater levels of epistatic incompatibilities and loss of Clp function when transformed into tobacco.

\section{MATERIALS AND METHODS}

\section{Construction of plastid transformation vectors for replacement of $c / p P 1$ in tobacco}

112 To replace the native $c / p P 1$ gene in the tobacco plastome with orthologous sequences from donor species, we relied on particle bombardment of leaf tissue and the natural homologous recombination activity within plastids (Svab and Maliga 1993). This strategy involved combining the desired donor clpP1 sequence with a selectable marker and flanking sequences from tobacco plastome that would serve as substrate for homologous recombination (Figure 2). A region of the plastome containing $958 \mathrm{bp}$ of the $p s b B$ gene and intergenic region between $c l p P 1$ and $p s b B$ (corresponding to plastome positions 74,728-75,686; GenBank accession KU199713.1) was amplified by PCR as a BamHIISmal fragment using psbBHR-S and psbBHR-AS primers (Table S1). The PCR product was cloned in a BamHI/Smal-linearized pBluescript KS $(+)$ phagemid (Stratagene) producing pBS-v1 (Figure 2). Also, a 3200-bp plastome fragment containing the $c / p P 1$ operon and intergenic region of $c / p P 1$ and psbB (corresponding to plastome position 71,528-74,728) was amplified as a Xhol/Smal fragment using ClpP1HR-S and ClpP1HR-AS primers (Table S1) and cloned in pBS- $v 1$ to produce pBS-v2. The chimeric spectinomycin resistance (aadA) construct with 16S rRNA promoter (Prrn) and psbA 3' 
125 regulatory regions (Svab and Maliga 1993) was synthesized and cloned into the Smal site in pBS- 12

126 to produce pBS-v3. The orientation of the insert was selected such that the transcription of aadA is

127 in the opposite direction of the clpP1 operon. A Sphl restriction site was introduced behind Smal at

128 the $5^{\prime}$ end of the aadA construct for exchange of the native tobacco clpP1 with counterparts from

129 donor species using a unique BstZ17/ restriction site in the $c / p P 1$ operon. Coding sequences from

130 clpP1 cDNA from donor species (tobacco, S. conica, S. latifolia, and S. noctiflora) were commercially

131 synthesized (GenScript, Piscataway, $\mathrm{NJ}$ ) with the native tobacco regulatory elements and an

132 introduced Sph/ restriction site and then cloned into pBS-v3, yielding pBS-v4, pBS-v6, pBS-v7 and

133 pBS- $v 9$, respectively), using Sphl and BstZ17/ cloning sites (Figure 2). Note that most angiosperms

134 have two introns in $c / p P 1$, so the absence of these introns in the cDNA donors represented a

135 difference relative to the genomic sequence (although the introns have already been lost from the

136 plastomes of S. conica and S. noctiflora). In addition, S. latifolia has a C-to-U RNA editing site in

137 codon 187 that is widespread in angiosperms but has been lost in S. conica, S. noctiflora, and

138 Nicotiana (Williams, et al. 2019). Therefore, for the S. latifolia cDNA construct, we used a T at this

139 position to mimic the edited state. Plasmids were transformed into $\mathrm{DH} 5 \alpha \mathrm{E}$. coli, propagated,

140 extracted by QIAGEN Plasmid Midi kit, and used for plastome transformation.

142 Plastid transformation and selection of transplastomic tobacco lines

143 Tobacco (N. tabacum cv. Petit Havana) plants were grown in a controlled growth chamber at 250

$144 \mu \mathrm{mol}$ photons $\mathrm{m}^{-2} \mathrm{~s}^{-1}$ light intensity $\left(16 \mathrm{~h}\right.$ day, $\left.25-27^{\circ} \mathrm{C}\right)$. Plastid transformation was performed

145 according to (Svab and Maliga 1993), using the biolistic PDS-1000/He particle bombardment system

146 (Bio-Rad). Young leaves of aseptically grown tobacco plants were bombarded with plasmid-DNA-

147 coated $0.6 \mu \mathrm{m}$ gold particles (Bio-Rad) and selected on RMOP media with $500 \mu \mathrm{g} \mathrm{ml}^{-1}$

148 spectinomycin (Svab and Maliga 1993). The primary spectinomycin-resistant shoots were confirmed

149 by testing for double resistance on RMOP medium containing spectinomycin and streptomycin (500

$150 \mu \mathrm{g} \mathrm{ml}^{-1}$ each) (Svab and Maliga 1993; Bock 2001). Transplastomic plants were subjected to 4 or 5

151 additional rounds of regeneration (Table S2) in the presence of spectinomycin to enrich the

152 transgenic plastome and to select against the wild type genome copies. Correct transgene insertion

153 and orientation were confirmed by PCR, and relative abundance of wild type and modified plastomes

154 was assessed by quantitative PCR (qPCR) and DNA gel (Southern) blotting (see below).

155 Following the antibiotic-selection regime described above, we removed the transplastomic

156 lines from selection to assess the stable maintenance of the edited plastomes. Using at least three

157 biological replicates for each of the Silene or tobacco control clpP1 replacements, we maintained

158 parallel cultures both with and without spectinomycin through two additional rounds of subculture

159 and regeneration. 


\section{PCR and QPCR assays of modified plastomes}

162 Total cellular DNA was prepared from regenerated leaves by the method of Doyle and Doyle (1990) and quantified by Qubit 2.0 Fluorometer (Invitrogen), using the dsDNA HS kit. PCR amplification was carried out using EmeraldAmp GT PCR Master Mix (Clontech, Takara) according to the manufacturer's protocol and the primers shown in Table S1 and Figure 2. PCR conditions were $2 \mathrm{~min}$ at $98^{\circ} \mathrm{C}$ followed by 35 cycles of $98^{\circ} \mathrm{C}$ for $10 \mathrm{~s}, 60^{\circ} \mathrm{C}$ for $30 \mathrm{~s}$ and $72{ }^{\circ} \mathrm{C}$ for a time period that

167 depended on the length of the target PCR product. PCR amplicons were electrophoresed on 1\%

$168(\mathrm{w} / \mathrm{v})$ agarose gels. For testing the heteroplasmic levels of wild type and transgenic clpP1 copies by

169 qPCR, $0.1 \mathrm{ng}$ total cellular DNA and $0.25 \mu \mathrm{M}$ sense and antisense primers were used in a $10 \mu \mathrm{l}$

170 reaction with iTaq Universal SYBR Green Supermix (Bio-Rad). The reaction volumes were heated at

$17195^{\circ} \mathrm{C}$ for $3 \mathrm{~min}$, followed by 40 cycles of $95^{\circ} \mathrm{C}$ for $10 \mathrm{~s}$ and $60{ }^{\circ} \mathrm{C}$ for $30 \mathrm{~s}$ and a subsequent melt

172 curve analysis on a Bio-Rad CFX96 Touch thermal cycler and real-time PCR detection system.

173 QClpP1-F and QCIpP1-R primers (Supplementary Table 1) located in exon 2 and intron 1,

174 respectively were used in $\mathrm{QPCR}$ to estimate the copy number of wild type tobacco genomic clpP1

175 (hereafter referred to as the exon/intron marker). The aadA transgene and the single-copy $p s b A$ gene were used as references for normalization. The amplification efficiency was calculated from the

177 slope of a standard curve obtained from 2-fold serial dilution of genomic DNA ranging from $5 \mathrm{ng}$ to $1780.078 \mathrm{ng}$.

For each of the four cDNA constructs (tobacco, S. conica, S. latifolia, and S. noctiflora), six

180 biological replicates were analyzed for each qPCR marker. Where possible, we chose independent

181 transformants for these replicates. However, in some cases there were fewer than six independent

182 transformant lines with the correct insert (five for N. tabacum, four for S. conica, and three for $S$.

183 latifolia). In these cases, we included two subcultures from the same primary transformant to obtain

184 the desired number of biological replicates. Each reaction was run in duplicate (technical replicates), 185 and the threshold cycle $\left(\mathrm{C}_{\mathrm{t}}\right)$ values for these two replicates were averaged for further analysis. After 186 removing lines from selection (see above), these qPCR assays were then repeated on parallel 187 cultures growing with and without spectinomycin.

We used a $\Delta \mathrm{C}_{\mathrm{t}}$ approach to estimate the relative abundance of wild type vs. transgenic plastome copies by comparing the $\mathrm{C}_{t}$ value for the exon/intron marker to the $\mathrm{C}_{\mathrm{t}}$ values of each of the 190 two aforementioned reference markers ( $\operatorname{ad} A$ and $p s b A$ ). Because the exon/intron maker should 191 only amplify in wild type copies and the aadA markers should only amplify in transgenic copies, a $192 \Delta \mathrm{C}_{\mathrm{t}}$ value (i.e., $\mathrm{C}_{\mathrm{t} \text { [exon/intron] }}-\mathrm{C}_{\mathrm{t}}$ [aadA] ) of 0 would indicate $50 / 50$ heteroplasmy, whereas positive $\Delta \mathrm{C}_{\mathrm{t}}$ 193 values for this comparison would indicate an excess of transgenic copies and negative values would 194 indicate an excess of wild type copies. The interpretation of comparisons to the $p s b A$ reference 
marker (i.e., $\Delta \mathrm{C}_{\mathrm{t}}=\mathrm{C}_{\mathrm{t} \text { [exon/intron] }}-\mathrm{C}_{\mathrm{t}}[p s b A]$ ) is similar except that the $p s b A$ marker should amplify in both wild type and transgenic plastomes. Therefore, for this comparison the 50/50 heteroplasmy point should correspond to a $C_{t}$ value of 1 rather than 0 . To test for significant difference among the four transgenic lines, a one-way ANOVA was performed with the aov function in R v3.6.3, followed by post hoc pairwise comparisons with the TukeyHSD function.

\section{Southern blotting}

202 Total genomic DNA extracted from wild type and regenerated leaves of transplastomic lines was

203 digested with $\mathrm{Nrul}$ and $\mathrm{Narl}$ restriction enzymes, electrophoresed in a $0.8 \%(\mathrm{w} / \mathrm{v})$ agarose gel,

204 transferred to a nylon membrane by capillary transfer, and UV cross-linked to the membrane

205 (Stratagene). Restriction enzymes were selected to produce two fragments (5211 and $2132 \mathrm{bp}$ ) from

206 the wild type plastome and one fragment $(\sim 7 \mathrm{~kb})$ from transplastomes (with slight differences in length

207 depending on the length of the donor clpP1 transgene), as the Narl restriction site is located inside the

208 second intron of $c / p P 1$ genomic sequence but not present in any of the cDNA transgenes. Two probes

209 (probe 1 and 2) from wild type tobacco plastome sequence flanking Narl restriction site were

210 amplified by PCR using primers described in Table S1 and labeled with Biotin DecaLabel DNA

211 Labeling Kit (Thermo Scientific). Therefore, while wild type samples are expected to show two bands

212 ( $\sim 2$ and $\sim 5 \mathrm{~kb})$, only one band $(\sim 7 \mathrm{~kb})$ is expected in homoplasmic transplastomic lines, and

213 heteroplasmic lines should have all three bands ( 7, $\sim 5$, and $\sim 2 \mathrm{~kb})$. Membranes containing digested

214 DNA from transplastomic plants and wild type tobacco were hybridized with denatured probes for 18

$215 \mathrm{~h}$ at $42^{\circ} \mathrm{C}$, washed, and incubated with a streptavidin HRP-conjugated antibody following the

216 protocol in the Thermo Scientific Pierce Chemiluminescent Nucleic Acid Detection kit.

Materials Availability

219 The constructs used for plastome transformation have been deposited to Addgene are available

220 under accessions 173794-173797.

\section{RESULTS AND DISCUSSION}

\section{Editing of tobacco plastome to replace native clpP1 sequence with Silene counterparts}

226 Using antibiotic selection, we confirmed that biolistic delivery was successful in introducing the aadA

227 marker into the tobacco plastome as part of each of the four clpP1 donor constructs (Figure 2).

228 Growth on spectinomycin plates identified numerous potential transformants. Because

229 spectinomycin resistance can arise by spontaneous mutations in plastid rRNA sequence (Svab and

230 Maliga 1993), dual selection with spectinomycin and streptomycin was conducted to distinguish 
231 spontaneous mutants from lines with true transgene-mediated resistance (Svab, et al. 1990). On

232 selection media, the calli of the resistant clones are green, while the sensitive ones are white

233 (Maliga, et al. 1990).

$234 \quad$ PCR screening with multiple primers pairs (Figure 2 and Table S1) was used to confirm that double-resistant lines contained the full transgenic construct inserted in the expected location. The presence of the full-length transgene was also confirmed by Southern blot analysis for select lines

237 (Figure S1). In some cases, lines carried the aadA selectable marker but exhibited evidence of

238 rearrangements or internal recombination events (examples shown Figure S2), which is not

239 surprising given the highly recombinational nature of plastomes. We restricted our analysis to lines

240 that produced PCR products with expected lengths for markers spanning the boundary between the

241 insert and flanking sequences on each side (Figure 3). Using this approach, we identified lines

242 derived from at least three independent transformation events for each of the four clpP1 donor

243 constructs (tobacco, S. conica, S. latifolia, and S. noctiflora cDNAs). Where necessary, we

244 propagated lines such that we had at least six biological replicates for each construct (Table S2).

\section{More divergent clpP1 donor sequences were restricted to lower heteroplasmic frequencies}

247 Typically, homoplasmic shoots are obtained after 3-5 months during the second or third cycle of 248 regeneration in the presence of antibiotic (Svab and Maliga 1993). However, even after five cycles of 249 regeneration, the frequency of wild type plastome copies detectable by qPCR was higher in the lines 250 carrying Silene clpP1 replacement constructs than in the control lines carry tobacco cDNA

251 replacements, indicating that these Silene replacement lines had generally not reached homoplasmy

252 (Figure 4). The measured primer efficiencies for all qPCR markers were very close to $100 \%$

253 (exon/intron: 102.0\%; aadA: 97.9\%; psbA: 98.0\%). Therefore, $\Delta \mathrm{C}_{\mathrm{t}}$ comparisons should provide an

254 accurate estimate of the relative abundance of modified vs. wild type plastome copies. Using 255 tobacco clpP1 cDNA itself to replace the corresponding tobacco genomic sequence was most 256 successful, but even for this control construct, there was a wide range among lines for the estimated 257 heteroplasmy levels (Table S3). The $\Delta \mathrm{C}_{\mathrm{t}}$ values for the tobacco cDNA lines imply that biological 258 replicates ranged anywhere from a $\sim 4$-fold to $\sim 30$-fold excess of modified plastomes compared to 259 wild-type, with the mean $\Delta \mathrm{C}_{\mathrm{t}}$ values indicating a $\sim 10$-fold excess. The three Silene donor sequences 260 all exhibited significantly lower levels of transgene enrichment than the tobacco cDNA control 261 (Figure 4). However, there was a clear distinction between the more conserved clpP1 sequence of

262 S. latifolia and its highly divergent congeners, as the former obtained higher levels of transgene 263 enrichment than either S. conica or $S$. noctiflora. The mean $\Delta C_{t}$ values for S. latifolia implied a $\sim 3.5-$

264 fold excess of the modified plastomes, whereas the S. conica and S. noctiflora lines both only 265 appeared to reach roughly 50/50 heteroplasmy levels on average (Figure 4). 

nuclear genome, which are known as "nupts" (Rousseau-Gueutin, et al. 2011). Therefore, it is likely that some of the wild type signal detected by qPCR actually results from amplifying nupts rather than true plastome copies. Unfortunately, a complete accounting of nupts is not available for $N$. tabacum, as insertions of organellar DNA can be very difficult to accurately identify even for some of the highest quality nuclear genome assemblies (Stupar, et al. 2001). However, because plastomes

272 typically occur in hundreds to thousands of copies per cell (Greiner, et al. 2020), the signal from

273 nupts should be relatively weak compared to true plastid DNA. Moreover, the same nuclear

274 background was used for all lines, so any contribution from nupts should be roughly equal across all

275 samples. Nevertheless, the presence of nupts can make for an ambiguous distinction between

276 homoplasmy and heteroplasmy in GPCR data. Therefore, we subjected transgenic lines to further

277 subculturing and took additional steps to test for homoplasmy as described below.

Homoplasmic replacement of native clpP1 obtained for tobacco cDNA control and S. latifolia clpP1 but not for S. noctiflora and S. conica donors

Using the transgenic lines described above, we established parallel cultures both with and without antibiotic selection and assayed the relative abundance of transgene ( $\operatorname{aad} A$ ) and wild-type (exon/intron) markers by qPCR (Figure 5, Table S4). Lines harboring tobacco and S. latifolia cDNA constructs maintained high transgene frequencies both with and without selection (Figure 5), raising the possibility that they had reached homoplasmy. In the absence of antibiotic selection, we would expect transgenes that were still heteroplasmic to reduce in frequency, especially if aadA expression is costly or the $c / p P 1$ replacement is not fully functional in a tobacco genetic background. In contrast sequences exhibited much lower transgene frequencies, indicative of heteroplasmy. As expected, the $S$. noctiflora lines generally showed a further reduction in transgene frequency when removed from antibiotic selection. Surprisingly, this was not the case for the $S$. conica lines, which remained at approximately the same frequencies regardless of whether they were cultured with or without antibiotics (Figure 5).

A Southern blot analysis helped explain this surprising qPCR result for the $S$. conica lines (Figure 6). Although they were originally confirmed to contain the full transgenic construct (Figure 3), we found that these $S$. conica lines had since undergone a recombination event between wild type and transgenic plastomes. Therefore, rather than being heteroplasmic, they were homoplasmic for a recombinant plastome that appeared to contain both the aad $A$ selection marker and the wild type genomic clpP1 sequence (resulting in the false appearance of a $\sim 50 / 50$ heteroplasmy in qPCR data). In contrast, the $S$. noctiflora lines still exhibited heteroplasmy for the wild type and transgenic plastomes, but most of these lines also showed evidence of recombinant haplotypes as well (Figure 
302 6). Therefore, it appears that persistent heteroplasmy resulting from transgenic clpP1 donor sequences that cannot replace the functionality of the native $c / p P 1$ gene provides an ongoing opportunity for recombination between wild type and transgenic plastomes that can resolve the conflicting selection pressures for $c / p P 1$ function and antibiotic resistance.

The Southern blot analysis supported the inference that all three analyzed lines carrying the tobacco cDNA transgene were homoplasmic (Figure 6). In contrast, only one of the three analyzed S. latifolia lines (7-dA) appeared homoplasmic for the full transgenic construct in the Southern blot analysis. We confirmed with Sanger sequencing that this line retained the full-length S. latifolia clpP1 coding sequence. Another S. Iatifolia line (7-7D) appeared homoplasmic for a haplotype with an internal recombination event, whereas a third line (7-9A) appeared nearly homoplasmic for the full

312 transgene but also contained a faintly detectable recombinant haplotype. The fact that only one of

313 the analyzed S. latifolia lines appears to have reached homoplasmy is consistent with the qPCR

314 results showing that the tobacco cDNA transgenes are generally easier to drive to high frequency

315 than the foreign S. latifolia transgene (Figure 4).

\section{Rapid clpP1 evolution and the generation of epistatic plastid-nuclear incompatibilities}

318 Our results support a model in which plastid-nuclear coevolution results in "matched" genotypes that are sensitive to disruption when novel genetic combinations are generated. Under the same selection conditions, Silene-derived clpP1 transgenes were limited to lower heteroplasmic levels than the tobacco cDNA control, and this gap was more pronounced for Silene donors with histories of accelerated clpP1 sequence evolution (Figure 4). Accordingly, additional antibiotic selection failed

323 to drive the divergent S. conica and S. noctiflora transgenes to homoplasmy, but we were able to 324 generate homoplasmic replacements for multiple tobacco cDNA control lines and a single S. latifolia line (i.e., the slowly evolving Silene donor; Figure 6). Previous analysis of chloroplast stromal protein fractions for Silene species with native gels and mass spectrometry has confirmed that the ClpP1 protein is still translated and appears to assemble with other subunits in the Clp proteolytic core

328 (Williams, et al. 2019). In addition, the rates of ClpP1 evolution strongly correlate with amino-acid 329 sequence divergence in interacting nuclear-encoded Clp subunits within Silene and more generally 330 across angiosperms (Rockenbach, et al. 2016; Williams, et al. 2019). Taken together, these 331 observations suggest that the lower relative abundance of the Silene clpP1 transgenes (and

332 especially those from S. conica and S. noctiflora; Figure 4) is caused by incompatibilities with the 333 nuclear-encoded Clp subunits in tobacco. The apparent emergence of incompatibilities based on $334 \quad c / p P 1$ divergence among such close relatives is striking, especially given the observation that human 335 (mitochondrial-targeted) $c l p P$ can partially substitute for the loss of its bacterial counterpart in Bacillus subtilis (Dittmar, et al. 2020) despite billions of years of evolutionary divergence. In that 
case, however, it should be noted that the Clp proteolytic core is homomeric (14 copies of the same subunit), in contrast to the highly heteromeric core of plastid Clp (Nishimura and van Wijk 2015).

Numerous studies have identified correlated rates of sequence evolution between genes in cytoplasmic and nuclear genomes and interpreted those as evidence of coevolution to maintain functional interactions (Osada and Akashi 2012; Sloan, Triant, Wu, et al. 2014; Pett and Lavrov 2015; Zhang, et al. 2015; Adrion, et al. 2016; Rockenbach, et al. 2016; Weng, et al. 2016; Zhang, et al. 2016; Havird, et al. 2017; Yan, et al. 2019; Forsythe, et al. 2021). Rarely, however, have such phylogenetic studies been coupled with functional tests for genetic incompatibilities. More generally, despite extensive evidence that hybridization can cause plastid-nuclear incompatibilities (Greiner, et al. 2011), the specific loci involved in those incompatibilities remain unclear except for a small number of cases (Schmitz-Linneweber, et al. 2005; Sobanski, et al. 2019; Zupok, et al. 2020). Our approach used here and previously (Kanevski, et al. 1999) to generate hybrid plastid-nuclear enzyme complexes with subunits derived from different species should be effective for testing for specific genetic incompatibilities.

We previously hypothesized that the rapid evolution and evidence for positive selection in Silene Clp complexes could reflect selfish dynamics and antagonistic coevolution between the plastome and nuclear genome (Rockenbach, et al. 2016). Under this hypothesis, we would predict that the divergent $c / p P 1$ genes are acting as selfish elements that increase their own transmission at the expense of organismal fitness. Potential mechanisms could include intracellular advantages, such as preferential rates of replication/division of plastomes or plastids carrying certain clpP1 variants, or organismal phenotypes such as male sterility that can boost transmission of maternally inherited organelle genomes (Havird, et al. 2019). We did not find any evidence for such a selfish advantage given the $S$. conica and $S$. noctiflora clpP1 transgenes were unable to reach homoplasmy and were limited to lower heteroplasmic levels than other constructs. These findings do not rule out the possibility that some form of selfish dynamics contributed to accelerated Clp evolution in these lineages. However, they suggest that if any selfish benefit did exist, it is greatly outweighed by incompatibilities that accumulated over the cumulative history of sequence divergence and coevolution that is disrupted by putting these genes in a tobacco background. One avenue for future

367 knockouts do not reach homoplasmy in tobacco (Shikanai, et al. 2001; Kuroda and Maliga 2003).

368 However, if they were able to reach higher heteroplasmic frequencies than the Silene replacements, 369 it would indicate that the sequence divergence in Silene does not only lead to loss of function in a 370 tobacco background but is actively harmful through dominant negative effects. In addition, the ability 371 to introduce targeted modifications through site-directed mutagenesis creates the opportunity to 372 dissect the specific changes within $c / p P 1$ that are responsible for the observed incompatibilities. 
373 Such techniques are promising for unraveling the history of cytonuclear coevolution at a detailed

374 molecular scale.

\section{ACKNOWLEDGEMENTS}

378 We thank Alissa Williams for comments on an earlier version of this manuscript and Amber Torres

379 and Matheus Fernandes Gyorfy for lab assistance. This work was supported by a grant from the

380 National Science Foundation (MCB-1733227).

\section{REFERENCES}

Adrion JR, White PS, Montooth KL. 2016. The roles of compensatory evolution and constraint in aminoacyl tRNA synthetase evolution. Molecular Biology and Evolution 33:152.

Aguileta G, Refregier G, Yockteng R, Fournier E, Giraud T. 2009. Rapidly evolving genes in pathogens: methods for detecting positive selection and examples among fungi, bacteria, viruses and protists. Infection, Genetics and Evolution 9:656-670.

Apitz J, Nishimura K, Schmied J, Wolf A, Hedtke B, van Wijk KJ, Grimm B. 2016. Posttranslational control of ALA synthesis includes GluTR degradation by Clp protease and stabilization by GluTR-binding protein. Plant Physiology 170:2040-2051.

Barnard-Kubow KB, So N, Galloway LF. 2016. Cytonuclear incompatibility contributes to the early stages of speciation. Evolution 70:2752-2766.

Bock R. 2001. Transgenic plastids in basic research and plant biotechnology. Journal of Molecular Biology 312:425-438.

Bogdanova VS, Zaytseva OO, Mglinets AV, Shatskaya NV, Kosterin OE, Vasiliev GV. 2015. Nuclearcytoplasmic conflict in pea (Pisum sativum L.) is associated with nuclear and plastidic candidate genes encoding acetyl-CoA carboxylase subunits. PloS one 10:e0119835.

Dittmar D, Reder A, Schlüter R, Riedel K, Hecker M, Gerth U. 2020. Complementation studies with human ClpP in Bacillus subtilis. Biochimica et Biophysica Acta (BBA)-Molecular Cell Research 1867:118744.

Doyle JJ, Doyle JL. 1990. Isolation of plant DNA from fresh tissue. Focus 12:39-40.

Erixon P, Oxelman B. 2008. Whole-gene positive selection, elevated synonymous substitution rates, duplication, and indel evolution of the chloroplast clpP1 gene. PloS one 3:e1386.

Fajardo D, Senalik D, Ames M, Zhu H, Steffan SA, Harbut R, Polashock J, Vorsa N, Gillespie E, Kron K. 2013. Complete plastid genome sequence of Vaccinium macrocarpon: structure, gene content, and rearrangements revealed by next generation sequencing. Tree Genetics \& Genomes 9:489498.

Forsythe ES, Williams AM, Sloan DB. 2021. Genome-wide signatures of plastid-nuclear coevolution point to repeated perturbations of plastid proteostasis systems across angiosperms. Plant Cell In Press.

Fujii S, Bond CS, Small ID. 2011. Selection patterns on restorer-like genes reveal a conflict between nuclear and mitochondrial genomes throughout angiosperm evolution. Proceedings of the National Academy of Sciences of the United States of America 108:1723-1728.

Gould SB, Waller RF, McFadden GI. 2008. Plastid evolution. Annual Review of Plant Biology 59:491-517.

Gray MW. 2012. Mitochondrial evolution. Cold Spring Harbor Perspectives in Biology 4:a011403.

Greiner S, Golczyk H, Malinova I, Pellizzer T, Bock R, Börner T, Herrmann RG. 2020. Chloroplast nucleoids are highly dynamic in ploidy, number, and structure during angiosperm leaf development. The Plant Journal 102:730-746.

Greiner S, Rauwolf U, Meurer J, Herrmann RG. 2011. The role of plastids in plant speciation. Molecular ecology 20:671-691. 
Haberle RC, Fourcade HM, Boore JL, Jansen RK. 2008. Extensive rearrangements in the chloroplast genome of Trachelium caeruleum are associated with repeats and tRNA genes. Journal of Molecular Evolution 66:350-361.

Hajdukiewicz PT, Allison LA, Maliga P. 1997. The two RNA polymerases encoded by the nuclear and the plastid compartments transcribe distinct groups of genes in tobacco plastids. EMBO Journal 16:4041-4048.

Havird JC, Forsythe ES, Williams AM, Werren JH, Dowling DK, Sloan DB. 2019. Selfish mitonuclear conflict. Current Biology 29:R496-R511.

Havird JC, Trapp P, Miller C, Bazos I, Sloan DB. 2017. Causes and consequences of rapidly evolving mtDNA in a plant lineage. Genome Biology and Evolution 9:323-336.

Hirao T, Watanabe A, Kurita M, Kondo T, Takata K. 2008. Complete nucleotide sequence of the Cryptomeria japonica D. Don. chloroplast genome and comparative chloroplast genomics: diversified genomic structure of coniferous species. BMC Plant Biology 8:70.

Huang C, Wang S, Chen L, Lemieux C, Otis C, Turmel M, Liu X-Q. 1994. The Chlamydomonas chloroplast clpP gene contains translated large insertion sequences and is essential for cell growth. Molecular and General Genetics 244:151-159.

Hughes AL, Nei M. 1988. Pattern of nucleotide substitution at major histocompatibility complex class I loci reveals overdominant selection. Nature 335:167-170.

Jafari F, Zarre S, Gholipour A, Eggens F, Rabeler RK, Oxelman B. 2020. A new taxonomic backbone for the infrageneric classification of the species-rich genus Silene (Caryophyllaceae). Taxon 69:337368.

Kanevski I, Maliga P, Rhoades DF, Gutteridge S. 1999. Plastome engineering of ribulose-1, 5bisphosphate carboxylase/oxygenase in tobacco to form a sunflower large subunit and tobacco small subunit hybrid. Plant Physiology 119:133-142.

Kim J, Olinares PD, Oh S-h, Ghisaura S, Poliakov A, Ponnala L, van Wijk KJ. 2013. Modified Clp protease complex in the ClpP3 null mutant and consequences for chloroplast development and function in Arabidopsis. Plant Physiology 162:157-179.

Kim J, Rudella A, Rodriguez VR, Zybailov B, Olinares PDB, van Wijk KJ. 2009. Subunits of the plastid ClpPR protease complex have differential contributions to embryogenesis, plastid biogenesis, and plant development in Arabidopsis. Plant Cell 21:1669-1692.

Koussevitzky S, Stanne TM, Peto CA, Giap T, Sjögren LL, Zhao Y, Clarke AK, Chory J. 2007. An Arabidopsis thaliana virescent mutant reveals a role for ClpR1 in plastid development. Plant Molecular Biology 63:85-96.

Kuroda H, Maliga P. 2003. The plastid clpP1 protease gene is essential for plant development. Nature 425:86-89.

Majeran W, Wollman F-A, Vallon O. 2000. Evidence for a role of ClpP in the degradation of the chloroplast cytochrome b6f complex. Plant Cell 12:137-149.

Maliga P, Moll B, Svab Z. 1990. Toward manipulation of plastid genes in higher plants. In: Zelitch I, editor. Perspectives in genetic and biochemical regulation of photosynthesis. New York. p. 133143.

Montandon C, Friso G, Liao J-YR, Choi J, van Wijk KJ. 2019. In Vivo Trapping of Proteins Interacting with the Chloroplast CLPC1 Chaperone: Potential Substrates and Adaptors. Journal of proteome research 18:2585-2600.

Moreno JC, Martínez-Jaime S, Schwartzmann J, Karcher D, Tillich M, Graf A, Bock R. 2018. Temporal proteomics of inducible RNAi lines of Clp protease subunits identifies putative protease substrates. Plant Physiology 176:1485-1508.

Moreno JC, Tiller N, Diez M, Karcher D, Tillich M, Schöttler MA, Bock R. 2017. Generation and characterization of a collection of knock-down lines for the chloroplast Clp protease complex in tobacco. Journal of Experimental Botany 68:2199-2218.

Nishimura K, Apitz J, Friso G, Kim J, Ponnala L, Grimm B, van Wijk KJ. 2015. Discovery of a unique Clp component, ClpF, in chloroplasts: a proposed binary ClpF-ClpS1 adaptor complex functions in substrate recognition and delivery. Plant Cell 27:2677-2691.

Nishimura K, Asakura Y, Friso G, Kim J, Oh S-h, Rutschow H, Ponnala L, van Wijk KJ. 2013. ClpS1 is a conserved substrate selector for the chloroplast Clp protease system in Arabidopsis. Plant Cell 25:2276-2301. 
Nishimura K, van Wijk KJ. 2015. Organization, function and substrates of the essential Clp protease system in plastids. Biochimica et Biophysica Acta-Bioenergetics 1847:915-930.

Nováková E, Zablatzká L, Brus J, Nesrstová V, Hanáček P, Kalendar R, Cvrčková F, Majeský L', Smýkal P. 2019. Allelic diversity of acetyl coenzyme A carboxylase accD/bccp genes implicated in nuclear-cytoplasmic conflict in the wild and domesticated pea (Pisum sp.). International Journal of Molecular Sciences 20:1773.

Osada N, Akashi H. 2012. Mitochondrial-nuclear interactions and accelerated compensatory evolution: evidence from the primate cytochrome $\mathrm{C}$ oxidase complex. Molecular Biology and Evolution 29:337.

Pett W, Lavrov DV. 2015. Cytonuclear interactions in the evolution of animal mitochondrial tRNA metabolism. Genome Biology and Evolution 7:2089-2101.

Pulido P, Llamas E, Llorente B, Ventura S, Wright LP, Rodríguez-Concepción M. 2016. Specific Hsp100 chaperones determine the fate of the first enzyme of the plastidial isoprenoid pathway for either refolding or degradation by the stromal Clp protease in Arabidopsis. PLoS Genetics 12:e1005824.

Rand DM, Haney RA, Fry AJ. 2004. Cytonuclear coevolution: the genomics of cooperation. Trends in Ecology \& Evolution 19:645-653.

Rautenberg A, Sloan DB, Aldén V, Oxelman B. 2012. Phylogenetic relationships of Silene multinervia and Silene section Conoimorpha (Caryophyllaceae). Systematic Botany 37:226-237.

Rockenbach KD, Havird JC, Monroe JG, Triant DA, Taylor DR, Sloan DB. 2016. Positive selection in rapidly evolving plastid-nuclear enzyme complexes. Genetics 204:1507-1522.

Roger AJ, Muñoz-Gómez SA, Kamikawa R. 2017. The origin and diversification of mitochondria. Current Biology 27:R1177-R1192.

Rousseau-Gueutin M, Ayliffe MA, Timmis JN. 2011. Conservation of plastid sequences in the plant nuclear genome for millions of years facilitates endosymbiotic evolution. Plant Physiology 157:2181-2193.

Schmitz-Linneweber C, Kushnir S, Babiychuk E, Poltnigg P, Herrmann RG, Maier RM. 2005. Pigment deficiency in nightshade/tobacco cybrids is caused by the failure to edit the plastid ATPase alphasubunit mRNA. Plant Cell 17:1815-1828.

Shikanai T, Shimizu K, Ueda K, Nishimura Y, Kuroiwa T, Hashimoto T. 2001. The chloroplast clpP gene, encoding a proteolytic subunit of ATP-dependent protease, is indispensable for chloroplast development in tobacco. Plant \& Cell Physiology 42:264-273.

Sjögren LL, Stanne TM, Zheng B, Sutinen S, Clarke AK. 2006. Structural and functional insights into the chloroplast ATP-dependent Clp protease in Arabidopsis. Plant Cell 18:2635-2649.

Sloan DB, Havird JC, Sharbrough J. 2017. The on-again, off-again relationship between mitochondrial genomes and species boundaries. Molecular ecology 26:2212-2236.

Sloan DB, Triant DA, Forrester NJ, Bergner LM, Wu M, Taylor DR. 2014. A recurring syndrome of accelerated plastid genome evolution in the angiosperm tribe Sileneae (Caryophyllaceae). Molecular phylogenetics and evolution 72:82-89.

Sloan DB, Triant DA, Wu M, Taylor DR. 2014. Cytonuclear interactions and relaxed selection accelerate sequence evolution in organelle ribosomes. Molecular Biology and Evolution 31:673-682.

Sloan DB, Warren JM, Williams AM, Wu Z, Abdel-Ghany SE, Chicco AJ, Havird JC. 2018. Cytonuclear integration and co-evolution. Nature Reviews Genetics 19:635-648.

Sobanski J, Giavalisco P, Fischer A, Kreiner JM, Walther D, Schöttler MA, Pellizzer T, Golczyk H, Obata T, Bock R. 2019. Chloroplast competition is controlled by lipid biosynthesis in evening primroses. Proceedings of the National Academy of Sciences 116:5665-5674.

Straub SC, Fishbein M, Livshultz T, Foster Z, Parks M, Weitemier K, Cronn RC, Liston A. 2011. Building a model: developing genomic resources for common milkweed (Asclepias syriaca) with low coverage genome sequencing. BMC Genomics 12:211.

Stupar RM, Lilly JW, Town CD, Cheng Z, Kaul S, Buell CR, Jiang J. 2001. Complex mtDNA constitutes an approximate $620-\mathrm{kb}$ insertion on Arabidopsis thaliana chromosome 2: implication of potential sequencing errors caused by large-unit repeats. Proceedings of the National Academy of Sciences of the United States of America 98:5099-5103.

Svab Z, Hajdukiewicz P, Maliga P. 1990. Stable transformation of plastids in higher plants. Proceedings of the National Academy of Sciences 87:8526-8530. 
Svab Z, Maliga P. 1993. High-frequency plastid transformation in tobacco by selection for a chimeric aadA gene. Proceedings of the National Academy of Sciences 90:913-917.

Tapken W, Kim J, Nishimura K, van Wijk KJ, Pilon M. 2015. The Clp protease system is required for copper ion-dependent turnover of the PAA 2/HMA 8 copper transporter in chloroplasts. New Phytologist 205:511-517.

Touzet P, Budar F. 2004. Unveiling the molecular arms race between two conflicting genomes in cytoplasmic male sterility? Trends in plant science 9:568-570.

Welsch R, Zhou X, Yuan H, Álvarez D, Sun T, Schlossarek D, Yang Y, Shen G, Zhang H, RodriguezConcepcion M. 2018. Clp protease and OR directly control the proteostasis of phytoene synthase, the crucial enzyme for carotenoid biosynthesis in Arabidopsis. Molecular Plant 11:149162.

Weng ML, Ruhlman TA, Jansen RK. 2016. Plastid-nuclear interaction and accelerated coevolution in plastid ribosomal genes in Geraniaceae. Genome Biology and Evolution 8:1824-1838.

Williams AM, Friso G, van Wijk KJ, Sloan DB. 2019. Extreme variation in rates of evolution in the plastid Clp protease complex. Plant Journal 98:243-259.

Williams AV, Boykin LM, Howell KA, Nevill PG, Small I. 2015. The complete sequence of the Acacia ligulata chloroplast genome reveals a highly divergent $c / p P 1$ gene. PloS one 10:e0125768.

Wu G-Z, Chalvin C, Hoelscher M, Meyer EH, Wu XN, Bock R. 2018. Control of retrograde signaling by rapid turnover of GENOMES UNCOUPLED1. Plant Physiology 176:2472-2495.

Yan Z, Ye G, Werren J. 2019. Evolutionary rate correlation between mitochondrial-encoded and mitochondria-associated nuclear-encoded proteins in insects. Molecular Biology and Evolution 36:1022-1036.

Yang Z. 2007. PAML 4: Phylogenetic Analysis by Maximum Likelihood. Molecular Biology and Evolution 24:1586-1591.

Yao X, Tang P, Li Z, Li D, Liu Y, Huang H. 2015. The first complete chloroplast genome sequences in Actinidiaceae: genome structure and comparative analysis. PloS one 10:e0129347.

Zhang J, Ruhlman TA, Sabir J, Blazier JC, Jansen RK. 2015. Coordinated rates of evolution between interacting plastid and nuclear genes in Geraniaceae. The Plant Cell 27:563-573.

Zhang J, Ruhlman TA, Sabir JS, Blazier JC, Weng ML, Park S, Jansen RK. 2016. Coevolution between nuclear-encoded DNA replication, recombination, and repair genes and plastid genome complexity. Genome Biology and Evolution 8:622-634.

Zhang Y, Ma J, Yang B, Li R, Zhu W, Sun L, Tian J, Zhang L. 2014. The complete chloroplast genome sequence of Taxus chinensis var. mairei (Taxaceae): loss of an inverted repeat region and comparative analysis with related species. Gene 540:201-209.

Zheng B, MacDonald TM, Sutinen S, Hurry V, Clarke AK. 2006. A nuclear-encoded ClpP subunit of the chloroplast ATP-dependent Clp protease is essential for early development in Arabidopsis thaliana. Planta 224:1103-1115.

Zupok A, Kozul D, Schöttler MA, Niehörster J, Garbsch F, Liere K, Malinova I, Bock R, Greiner S. 2020. A photosynthesis operon in the chloroplast genome drives speciation in evening primroses. bioRxiv:2020.2007.2003.186627. 


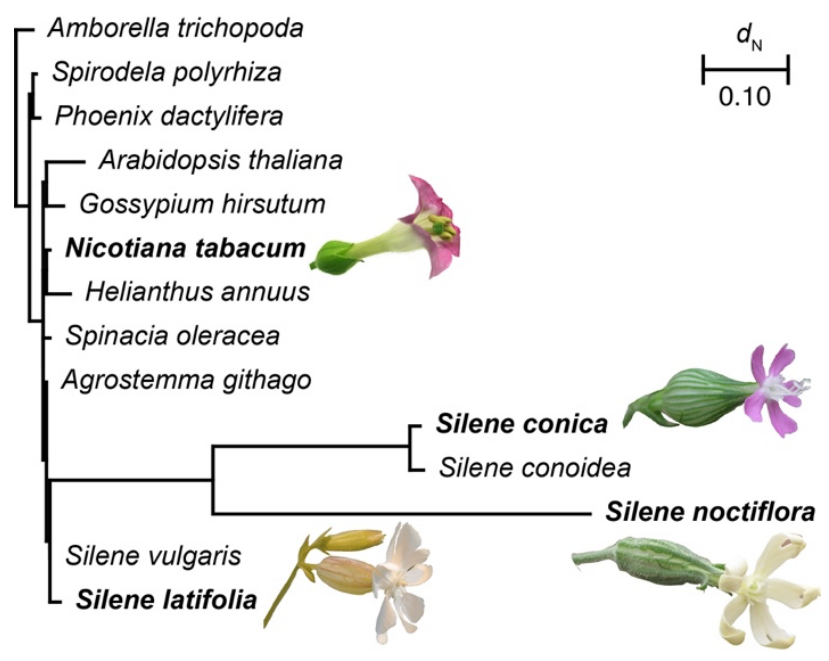

Figure 1. Variation in $c / p P 1$ nonsynonymous substitutions rate $\left(d_{N}\right)$ in Silene species relative to a sample of diverse angiosperms with relatively conserved copies of $c / p P 1$. Branch lengths were estimated with codeml within the PAML v4.9j package (Yang 2007), using a constrained topology. Silene noctiflora was constrained to be sister to the $S$. conica/conoidea lineage, although support for this relationship has been weak or inconsistent in previous studies (Rautenberg, et al. 2012; Havird, et al. 2017; Jafari, et al. 2020). The species used in this study are highlighted in bold text and accompanied by a flower image. 
A

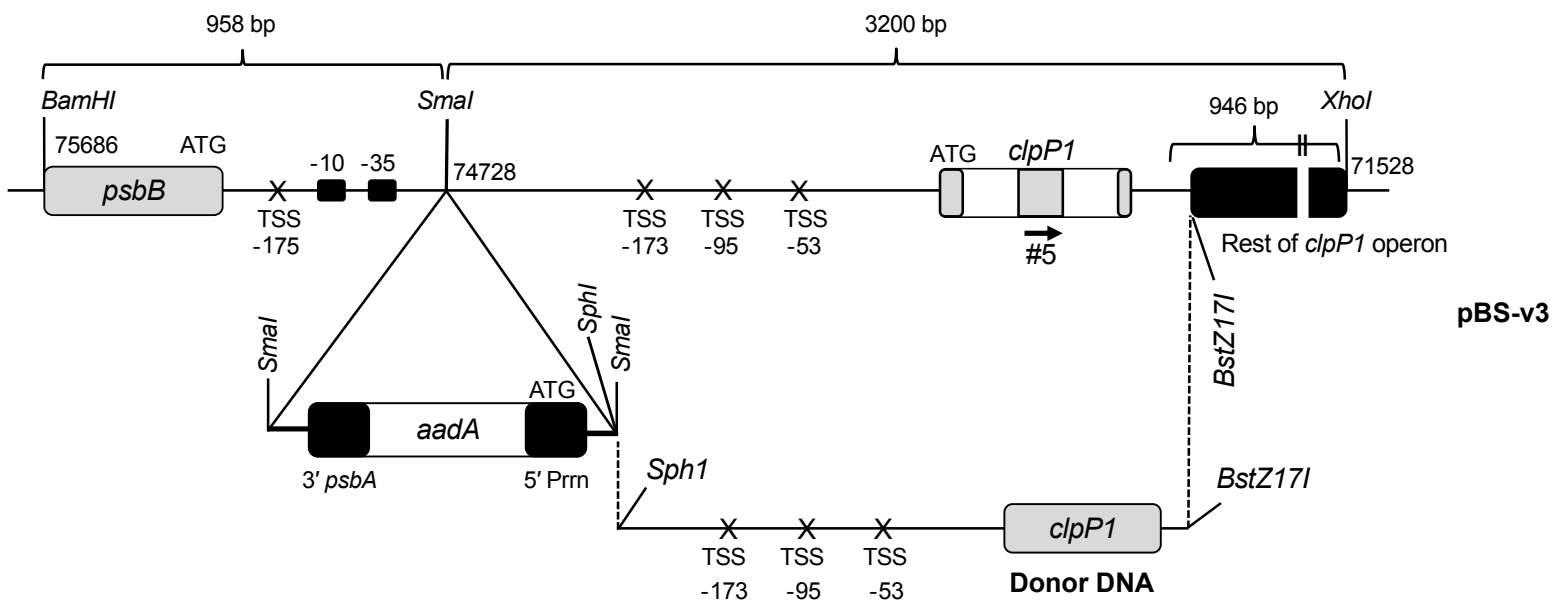

B

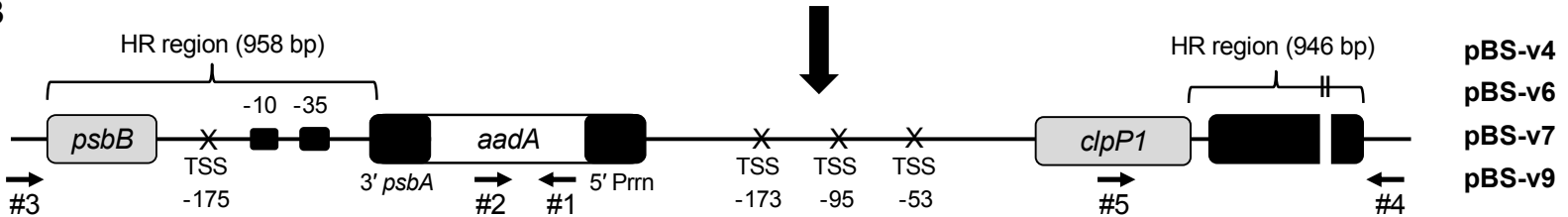

Figure 2. Targeted replacement of $c l p P 1$ in the tobacco plastome with cDNA counterparts from different Silene species. (A) Physical map of the targeting region in the plastome of wild type tobacco cloned in pBluescript KS (+) plasmid (pBS-v3, see text for details). The chimeric selectable marker gene aadA conferring resistance to spectinomycin and streptomycin is driven by the rRNA operon promoter ( $5^{\prime}$ Prrn). The $3^{\prime}$ untranslated region of the $p s b A$ gene ( $3^{\prime} p s b A$ ) was added to stabilize the mRNA (Svab and Maliga 1993). (B) Plastid-targeting region with flanking homologous recombination sequences (HR regions), donor clpP1 coding sequences, and aadA cassette. The aad $A$ cassette was introduced in antisense direction relative to c/pP1 operon. Restriction sites used for cloning and replacement are indicated. Numbered horizontal arrows represent primers used in PCR validation of insertion and orientation (Table S1). Transcription start sites (TSSs) are indicated in the intergenic regions between the $p s b B$ gene and clpP1 operon (Hajdukiewicz, et al. 1997). Certain regions of the map are expanded and not drawn to scale for the sake of clarity. 


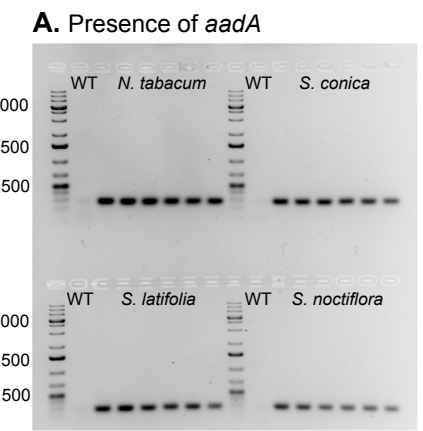

B. Correct insertion on $p s b B$ side
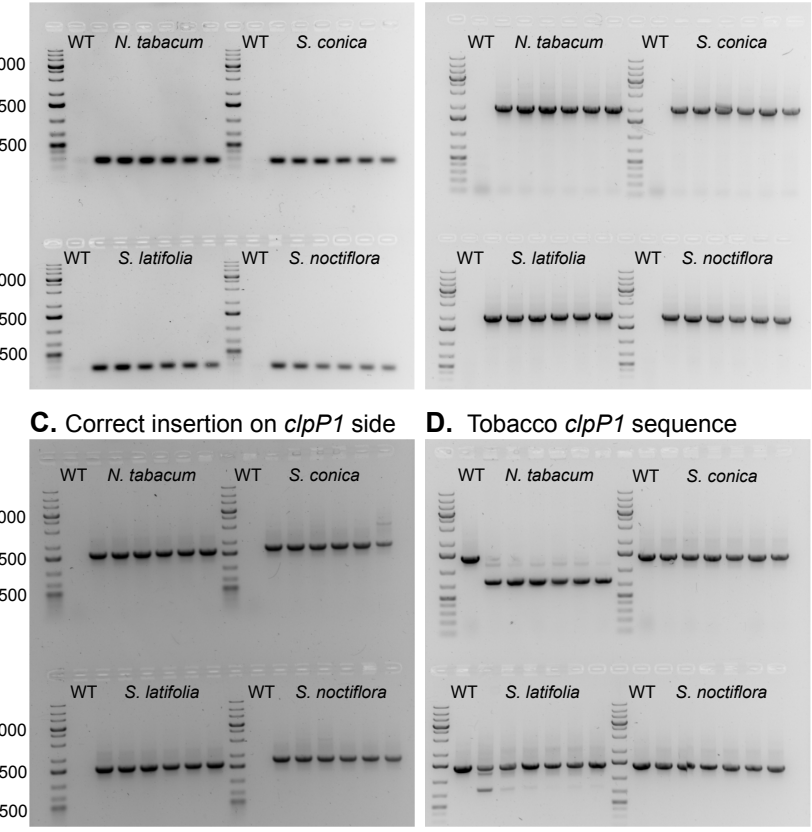

\section{Tobacco $c / p P 1$ sequence}

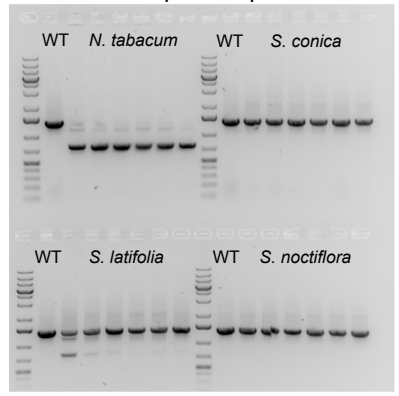

Figure 3. Confirmation of proper insertion and orientation of $c / p P 1$ replacement constructs. Each gel shows PCR products from amplification of total-cellular DNA extracted from wild type (WT) tobacco and the six replicate transgenic lines for each of the four clpP1 cDNA replacement constructs (indicated by the name of the donor species; Table S2). (A) Detection of aadA selectable marker gene with primers \#1 and \#2; expected product size $276 \mathrm{bp}$. (B) Confirmation of proper insertion of aad $A$ transgene with flanking sequence on the $p s b B$ side, using primers $\# 1$ and \#3; expected product size $2002 \mathrm{bp}$. (C) Confirmation of proper insertion of aadA transgene with flanking sequence on the clpP1 side, using primers \#2 and \#4; expected product size $1554 \mathrm{bp}$. (D) Amplification of clpP1 and flanking sequence with a tobacco-specific primer (\#5) and primer \#4; expected product size of $1400 \mathrm{bp}$ for native genomic DNA and $776 \mathrm{bp}$ for cDNA. The Silene cDNA constructs are not expected to amplify with this marker except for S. latifolia, which appears to show weak crossreactivity presumably because of its greater degree of sequence similarity with tobacco. Sizes of the dark marker bands (in bp) are shown to the left. All primer numbers refer to Figure 2 and Table S1. 

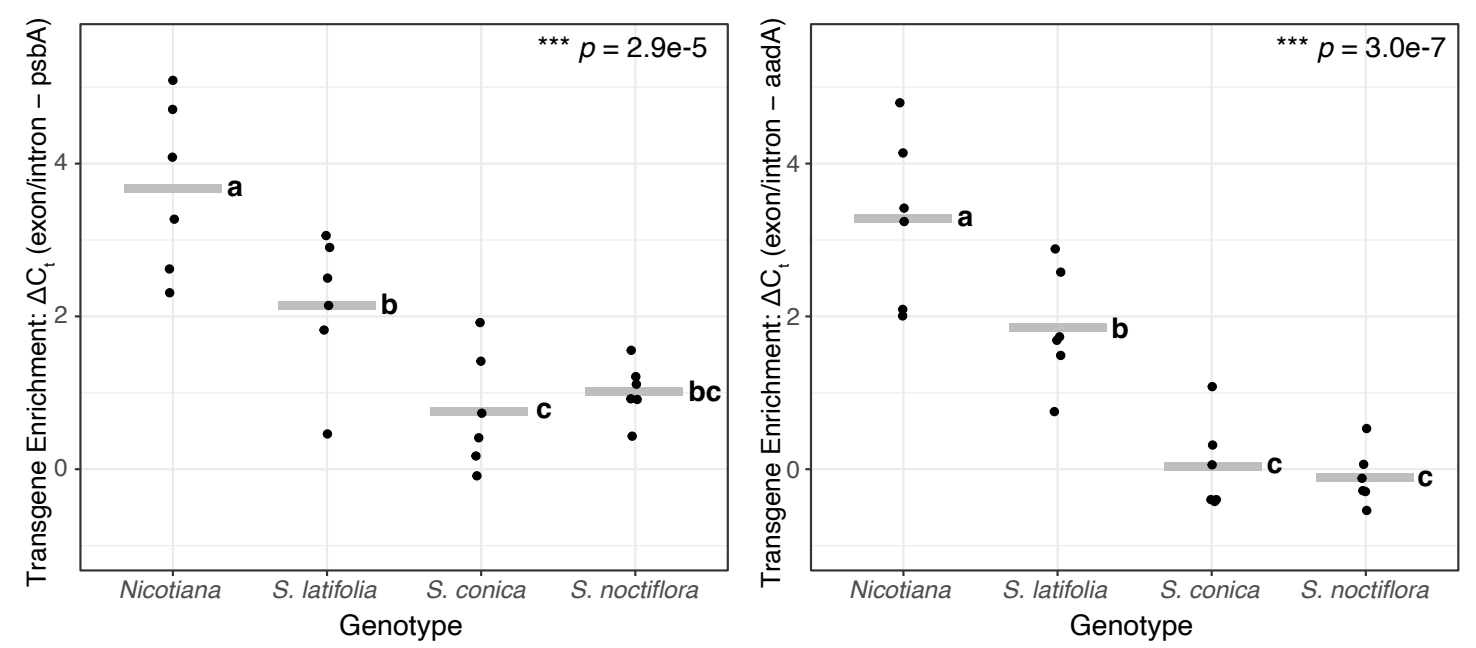

Figure 4. Varying levels of heteroplasmy obtained for different replacements of the native clpP1 sequence in tobacco. Levels of enrichment by antibiotic selection for the transgenic plastomes were inferred by qPCR analysis, comparing a wild type marker (spanning an exon/intron junction in the native $c / p P 1)$ against a shared reference gene ( $p s b A$; left) or the antibiotic resistance maker in the transgenic cassette (aadA; right). Higher $\Delta \mathrm{C}_{\mathrm{t}}$ values are indicative of reduced abundance of the wild type maker and greater enrichment of transgenic plastomes. Each black point represents a biological replicate (averaged from two technical replicates), and gray bars indicate the mean value for that donor sequence. Statistical significance was assessed with a one-way ANOVA. Lowercase letters indicate significant pairwise differences as identified by post hoc Tukey's HSD tests. 


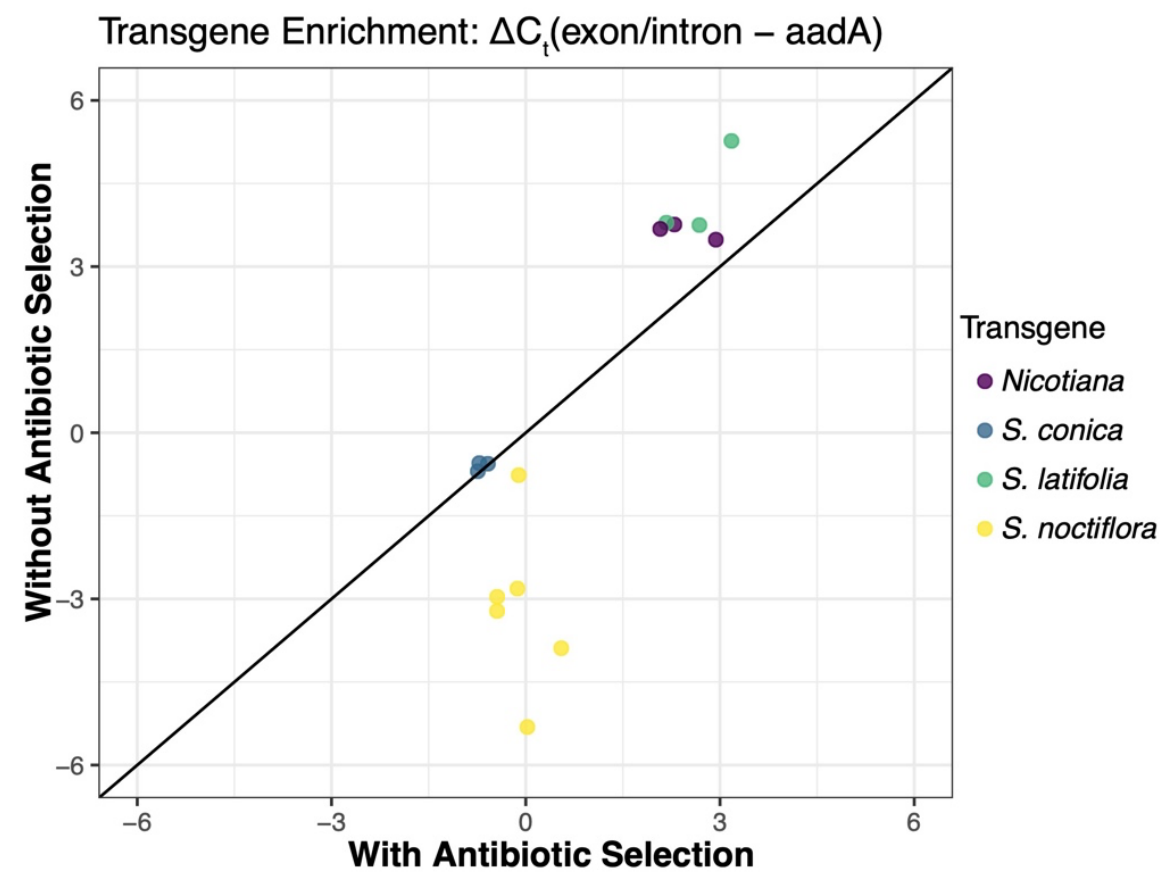

Figure 5. qPCR analysis of transplastomic lines grown in parallel cultures either with or without antibiotic selection. Each point represents a transplastomic line and the corresponding transgene enrichment values under the two selection regimes. qPCR analysis compared a wild type marker (spanning an exon/intron junction in the native clpP1) against the antibiotic resistance maker in the transgenic cassette (aadA). Higher $\Delta \mathrm{C}_{\mathrm{t}}$ values are indicative of reduced abundance of the wild type maker and greater enrichment of transgenic plastomes. The black diagonal line represents the 1:1 line. Points falling below that line indicate that the transgene dropped in frequency in the culture propagated without antibiotic selection. 


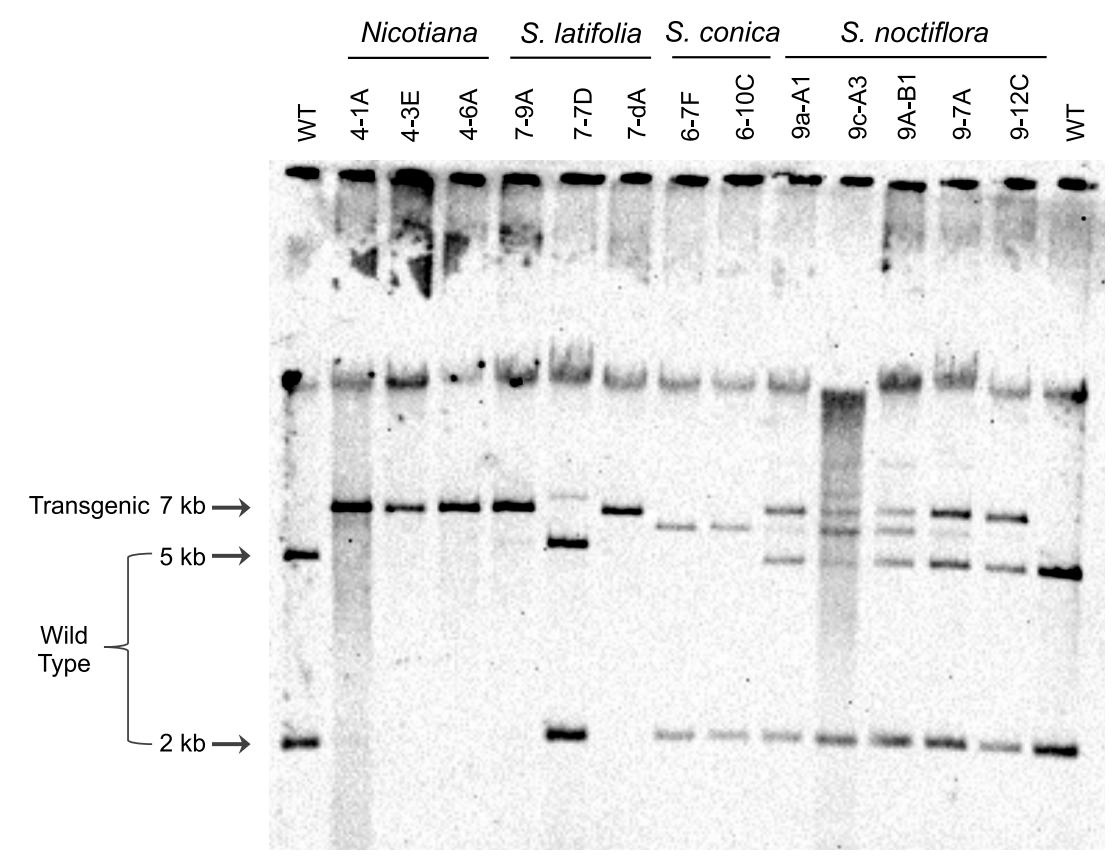

Figure 6. Southern blot analysis in which transplastomes should produce a single 7-kb band while wild type plastomes should produce both $5-\mathrm{kb}$ and $2-\mathrm{kb}$ bands as indicated. All three tobacco cDNA lines and the $S$. latifolia 7-dA line appear to be homoplasmic for the transplastome based on the absence of other detectable bands. All other lines are heteroplasmic for wild type and transgenic plastome, contain a recombinant haplotype, or both. The analysis was performed on samples maintained on antibiotic selection after parallel cultures were set up both with and without antibiotics (see main text). 
Table S1. Primer sequences. Underlined sequences represent introduced restriction sites for cloning. Primer names parenthetically labeled \#1 to \#7 refer to locations described in Figure 2.

\begin{tabular}{|c|c|c|}
\hline Primer name & Sequences $\left(5^{\prime}-3^{\prime}\right)$ & Purpose \\
\hline ClpP1HR-S & CCGCTCGAGTCCAATGGCTTTGGCTACTCTAACCT & \multirow[t]{5}{*}{ Cloning of HR fragment } \\
\hline ClpP1HR-AS & TCC $\underline{\text { CCCGGGCATTTTCTATGAGCGAATGAGTCCA }}$ & \\
\hline psbBHR-S & TCCCCCGGGGGATCAACTCCCCCATTGCGTATTG & \\
\hline psbBHR-AS & CGCGGATCCCAGCAGCGATACTACTGGAAAGGA & \\
\hline CIpP1HR-S & CCG $\underline{\text { CTCGAGTCCAATGGCTTTGGCTACTCTAACCT }}$ & \\
\hline $\operatorname{aadA1F}(\# 1)$ & TTGGATACAGTTGTAGGGAG & \multirow{2}{*}{$\begin{array}{l}\text { Detection of aadA selection } \\
\text { marker }\end{array}$} \\
\hline aadA2R (\#2) & GGAGAATCTCGCTCTCTCCA & \\
\hline psbBHR-1 (\#3) & CAATCGGGGTTGTTGCCGAACCAT & $\begin{array}{l}\text { Correct insertion at } p s b B \text { side } \\
\text { with primer \#1 }\end{array}$ \\
\hline Clp1seq1 (\#4) & TCATACACAATAGAGGGATATG & $\begin{array}{l}\text { Correct insertion at } c / p P 1 \text { side } \\
\text { with primer \#2 }\end{array}$ \\
\hline Clp1seqS (\#5) & GGTAATACCTGGGGTGGCTAT & $\begin{array}{l}\text { Amplification of tobacco } \\
\text { sequence with primer \#4 }\end{array}$ \\
\hline QCIpP1-F & CGCTATCAACCTCTTGGCCTA & \multirow{2}{*}{$\begin{array}{l}\text { Homoplasmy testing by } \\
\text { QPCR }\end{array}$} \\
\hline QClpP1-R & GGACTGGAATCTATACATTGA & \\
\hline aadA2F & GAAGCCACACAGTGATATTGA & \multirow{2}{*}{$\begin{array}{l}\text { Quantification of aadA in } \\
\text { QPCR }\end{array}$} \\
\hline aadA2R & GGAGAATCTCGCTCTCTCCA & \\
\hline psbA-F & CCTCCAGTAGACATTGATGGTA & \multirow{2}{*}{$\begin{array}{l}\text { Quantification of } p s b A \text { in } \\
\text { QPCR }\end{array}$} \\
\hline psbA-R & CCATTCATCAACGGATGCCGCT & \\
\hline Probe 1-F & CGAAAGCTTGATGCAAATAAACGA & \multirow{2}{*}{$\begin{array}{l}\text { Amplification of DNA fragment } \\
\text { for biotin labeled probe } 1 \text { used } \\
\text { in Southern }\end{array}$} \\
\hline Probe 1-R & CTTATTAGAAATACAAGACAGCCAATC & \\
\hline Probe 2-F & ATGGGTTTGCCTTGGTATCGTGTTC & $\begin{array}{l}\text { Making probe } 2 \text { with reverse } \\
\text { primer \#3 for Southern }\end{array}$ \\
\hline
\end{tabular}


bioRxiv preprint doi: https://doi.org/10.1101/2021.07.13.452280; this version posted July 14,2021 . The copyright holder for this preprint (which

was not certified by peer review) is the author/funder, who has granted bioRxiv a license to display the preprint in perpetuity. It is made available under aCC-BY-NC 4.0 International license.

Table S2. Six biological replicates from each transplastomic cDNA replacement line. Pairs shown in cells without divider lines are subcultures derived from the same primary transformant. Values in parenthesis indicate the number of regeneration cycles of the different transplastomic lines in selection media.

\begin{tabular}{|c|c|c|c|}
\hline \multirow{3}{*}{$\begin{array}{l}\text { N. tabacum } \\
4-1 \mathrm{~A}(5) \\
4-1 \mathrm{~B}(5)\end{array}$} & S. conica & $\begin{array}{l}\text { S. latifolia } \\
7-1 \mathrm{~B}(5) \\
7-1 \mathrm{C}(5)\end{array}$ & S. noctiflora \\
\hline & \multirow{2}{*}{$\begin{array}{l}6-3 A(5) \\
6-3 B(5)\end{array}$} & \multirow{2}{*}{$\begin{array}{l}7-1 B(5) \\
7-1 C(5)\end{array}$} & 9a-A (5) \\
\hline & & & $9 c-A(5)$ \\
\hline $4-3 E(5)$ & $6-5 C(5)$ & \multirow{2}{*}{$\begin{array}{l}7-9 A(5) \\
7-9 B(5)\end{array}$} & $9 d-B(5)$ \\
\hline $4-6 A(5)$ & $6-7 F(5)$ & & $9 A-B(4)$ \\
\hline 4-7B (5) & \multirow{2}{*}{$\begin{array}{l}6-10 B(4) \\
6-10 C(4)\end{array}$} & \multirow{2}{*}{$\begin{array}{l}7 d-A(4) \\
7 d-C(4)\end{array}$} & 9-7A (5) \\
\hline $4 b-A 1(5)$ & & & $9-12 C(4)$ \\
\hline $\begin{array}{l}5 \text { independent } \\
\text { transformants }\end{array}$ & $\begin{array}{l}4 \text { independent } \\
\text { transformants }\end{array}$ & $\begin{array}{l}3 \text { independent } \\
\text { transformants }\end{array}$ & $\begin{array}{l}6 \text { independent } \\
\text { transformants }\end{array}$ \\
\hline
\end{tabular}


bioRxiv preprint doi: https://doi.org/10.1101/2021.07.13.452280; this version posted July 14, 2021. The copyright holder for this preprint (which

was not certified by peer review) is the author/funder, who has granted bioRxiv a license to display the preprint in perpetuity. It is made available under aCC-BY-NC 4.0 International license.

Table S3. qPCR data from Figure 4 for estimating transgene enrichment relative to wild type plastomes

\begin{tabular}{|c|c|c|c|c|c|c|c|c|c|c|c|c|c|c|}
\hline \multirow{2}{*}{$\begin{array}{l}c / p P 1 \\
\text { Genotype }\end{array}$} & \multirow[b]{2}{*}{ Sample } & \multicolumn{3}{|c|}{$\operatorname{aad} A\left(\mathrm{C}_{\mathrm{t}}\right)$} & \multicolumn{3}{|c|}{$\operatorname{psbA}\left(\mathrm{C}_{\mathrm{t}}\right)$} & \multicolumn{3}{|c|}{ exon/intron $\left(C_{t}\right)$} & \multicolumn{2}{|c|}{$\Delta \mathrm{C}_{\mathrm{t}}$ (exon/intron) } & \multicolumn{2}{|c|}{ Transgene: WT Ratio } \\
\hline & & Rep1 & Rep2 & Mean & Rep1 & Rep2 & Mean & Rep1 & Rep2 & Mean & aadA & psbA & $\operatorname{aadA}\left(2^{\Delta C t}\right)$ & $\operatorname{psbA}\left(2^{\Delta \mathrm{Ct}}-1\right)$ \\
\hline Nicotiana & $4-1 \mathrm{~A}$ & 23.15 & 23.15 & 23.15 & 23.13 & 22.57 & 22.85 & 25.09 & 25.23 & 25.16 & 2.01 & 2.31 & 4.03 & 3.96 \\
\hline Nicotiana & $4-1 \mathrm{~B}$ & 21.78 & 21.61 & 21.69 & 21.16 & 21.07 & 21.12 & 25.95 & 25.71 & 25.83 & 4.14 & 4.71 & 17.63 & 25.17 \\
\hline Nicotiana & $4-6 \mathrm{~A}$ & 21.63 & 21.83 & 21.73 & 20.78 & 21.36 & 21.07 & 25.27 & 25.03 & 25.15 & 3.42 & 4.08 & 10.70 & 15.91 \\
\hline Nicotiana & $4-7 \mathrm{~B}$ & 23.19 & 23.21 & 23.20 & 22.86 & 22.48 & 22.67 & 25.38 & 25.20 & 25.29 & 2.09 & 2.62 & 4.26 & 5.15 \\
\hline Nicotiana & $4-3 E$ & 22.58 & 22.64 & 22.61 & 22.51 & 22.65 & 22.58 & 26.01 & 25.68 & 25.85 & 3.24 & 3.27 & 9.45 & 8.65 \\
\hline Nicotiana & $4 b-A 1$ & 21.46 & 21.55 & 21.51 & 21.16 & 21.28 & 21.22 & 26.29 & 26.33 & 26.31 & 4.80 & 5.09 & 27.86 & 33.06 \\
\hline S. conica & $6-3 A$ & 20.81 & 20.73 & 20.77 & 19.57 & 19.78 & 19.68 & 21.15 & 21.03 & 21.09 & 0.32 & 1.41 & 1.25 & 1.66 \\
\hline S. conica & $6-3 B$ & 21.95 & 21.89 & 21.92 & 21.12 & 21.05 & 21.08 & 22.97 & 23.04 & 23.00 & 1.08 & 1.92 & 2.11 & 2.78 \\
\hline S. conica & $6-7 \mathrm{~F}$ & 21.80 & 22.02 & 21.91 & 20.97 & 21.22 & 21.10 & 21.81 & 21.21 & 21.51 & -0.40 & 0.41 & 0.76 & 0.33 \\
\hline S. conica & $6-10 B$ & 21.60 & 22.01 & 21.80 & 22.01 & 21.38 & 21.69 & 22.58 & 21.14 & 21.86 & 0.06 & 0.17 & 1.04 & 0.13 \\
\hline S. conica & $6-5 C$ & 21.40 & 21.73 & 21.57 & 20.52 & 20.35 & 20.43 & 21.15 & 21.18 & 21.16 & -0.40 & 0.73 & 0.76 & 0.66 \\
\hline S. conica & $6-10 \mathrm{C}$ & 21.56 & 21.47 & 21.52 & 21.18 & 21.20 & 21.19 & 21.08 & 21.12 & 21.10 & -0.42 & -0.09 & 0.75 & $\mathrm{~N} / \mathrm{A}$ \\
\hline S. Iatifolia & $7 d-C$ & 21.66 & 21.52 & 21.59 & 21.22 & 21.13 & 21.17 & 23.30 & 23.33 & 23.31 & 1.73 & 2.14 & 3.32 & 3.41 \\
\hline S. latifolia & $7 \mathrm{~d}-\mathrm{A}$ & 22.18 & 22.40 & 22.29 & 22.39 & 21.56 & 21.98 & 24.95 & 24.79 & 24.87 & 2.58 & 2.90 & 5.98 & 6.46 \\
\hline S. latifolia & $7-9 A$ & 21.59 & 21.95 & 21.77 & 21.49 & 21.40 & 21.45 & 23.17 & 23.35 & 23.26 & 1.49 & 1.82 & 2.81 & 2.53 \\
\hline S. latifolia & $7-1 \mathrm{~B}$ & 23.38 & 23.33 & 23.35 & 22.70 & 22.39 & 22.55 & 25.02 & 25.07 & 25.05 & 1.69 & 2.50 & 3.23 & 4.66 \\
\hline S. Iatifolia & $7-1 C$ & 22.21 & 22.37 & 22.29 & 22.12 & 22.12 & 22.12 & 25.18 & 25.17 & 25.18 & 2.88 & 3.06 & 7.36 & 7.34 \\
\hline S. latifolia & $7-9 B$ & 22.38 & 22.50 & 22.44 & 22.89 & 22.57 & 22.73 & 23.08 & 23.29 & 23.19 & 0.75 & 0.46 & 1.68 & 0.38 \\
\hline S. noctiflora & $9 a-A$ & 21.97 & 21.83 & 21.90 & 21.04 & 20.69 & 20.87 & 22.43 & 22.42 & 22.43 & 0.53 & 1.56 & 1.44 & 1.95 \\
\hline S. noctiflora & $9 c-A$ & 21.33 & 21.50 & 21.41 & 20.23 & 20.17 & 20.20 & 21.16 & 21.08 & 21.12 & -0.29 & 0.92 & 0.82 & 0.89 \\
\hline S. noctiflora & $9-7-A$ & 21.98 & 22.41 & 22.20 & 21.22 & 21.23 & 21.23 & 21.67 & 21.64 & 21.66 & -0.54 & 0.43 & 0.69 & 0.35 \\
\hline S. noctiflora & $9-12 C$ & 21.67 & 21.83 & 21.75 & 20.29 & 20.43 & 20.36 & 21.41 & 21.52 & 21.47 & -0.28 & 1.11 & 0.82 & 1.16 \\
\hline S. noctiflora & $9 d-B$ & 22.74 & 22.46 & 22.60 & 21.62 & 21.52 & 21.57 & 22.35 & 22.61 & 22.48 & -0.12 & 0.91 & 0.92 & 0.88 \\
\hline S. noctiflora & $9 A-B$ & 21.41 & 21.63 & 21.52 & 20.34 & 20.37 & 20.36 & 21.30 & 21.85 & 21.57 & 0.06 & 1.21 & 1.04 & 1.31 \\
\hline
\end{tabular}


bioRxiv preprint doi: https://doi.org/10.1101/2021.07.13.452280; this version posted July 14, 2021. The copyright holder for this preprint (which

was not certified by peer review) is the author/funder, who has granted bioRxiv a license to display the preprint in perpetuity. It is made available under aCC-BY-NC 4.0 International license.

Table S4. qPCR data from Figure 5 for estimating transgene enrichment relative to wild type plastomes

\begin{tabular}{|c|c|c|c|c|c|c|c|c|c|c|c|c|c|}
\hline \multicolumn{3}{|l|}{$c / p P 1$} & \multicolumn{3}{|c|}{$\operatorname{aad} A\left(\mathrm{C}_{\mathrm{t}}\right)$} & \multicolumn{3}{|c|}{$\operatorname{psbA}\left(\mathrm{C}_{\mathrm{t}}\right)$} & \multicolumn{3}{|c|}{ exon/intron $\left(C_{t}\right)$} & \multicolumn{2}{|c|}{$\Delta \mathbf{C}_{\mathrm{t}}$ (exon/intron) } \\
\hline Genotype & Sample & Antibiotic & Rep1 & Rep2 & Mean & Rep1 & Rep2 & Mean & Rep1 & Rep2 & Mean & $\operatorname{aad} A$ & psbA \\
\hline Nicotiana & $4-1 \mathrm{~A}$ & No & 22.25 & 22.39 & 22.32 & 22.04 & 22.23 & 22.13 & 26.06 & 26.10 & 26.08 & 3.83 & 3.95 \\
\hline Nicotiana & $4-1 A$ & Yes & 23.31 & 23.18 & 23.25 & 22.41 & 22.40 & 22.40 & 25.49 & 25.59 & 25.54 & 2.23 & 3.14 \\
\hline Nicotiana & $4-3$ & Yes & 20.76 & 20.65 & 20.71 & 20.07 & 19.96 & 20.01 & 22.61 & 22.96 & 22.79 & 2.02 & 2.77 \\
\hline Nicotiana & $4-6$ & No & 20.90 & 20.55 & 20.72 & 20.36 & 20.24 & 20.30 & 24.19 & 24.23 & 24.21 & 3.31 & 3.91 \\
\hline S. conica & $6-10 B$ & Yes & 20.61 & 20.49 & 20.55 & 20.16 & 20.27 & 20.21 & 20.02 & 19.91 & 19.96 & -0.65 & -0.25 \\
\hline S. conica & $6-10 C$ & No & 21.16 & 21.18 & 21.17 & 20.56 & 20.56 & 20.56 & 20.32 & 20.63 & 20.48 & -0.69 & -0.09 \\
\hline S. conica & $6-10 c$ & Yes & 21.93 & 21.74 & 21.84 & 21.03 & 21.02 & 21.02 & 21.13 & 21.07 & 21.10 & -0.84 & 0.08 \\
\hline S. conica & $6-7 F$ & No & 21.86 & 21.99 & 21.93 & 21.17 & 21.35 & 21.26 & 21.45 & 21.31 & 21.38 & -0.48 & 0.12 \\
\hline S. conica & $6-7 F$ & Yes & 22.33 & 22.26 & 22.30 & 21.87 & 21.83 & 21.85 & 21.61 & 21.55 & 21.58 & -0.75 & -0.27 \\
\hline S. latifolia & $7-7 D$ & No & 20.22 & 20.21 & 20.21 & 19.60 & 19.92 & 19.76 & 25.39 & 25.58 & 25.48 & 5.26 & 5.72 \\
\hline S. Iatifolia & 7-dA & No & 20.39 & 20.51 & 20.45 & 19.72 & 19.87 & 19.80 & 24.19 & 24.20 & 24.20 & 3.81 & 4.40 \\
\hline S. Iatifolia & 7-dA & Yes & 20.61 & 20.41 & 20.51 & 20.22 & 20.09 & 20.16 & 23.17 & 23.22 & 23.19 & 2.58 & 3.04 \\
\hline S. noctiflora & $9-12 \mathrm{C}$ & No & 22.17 & 20.96 & 21.56 & 19.36 & 19.01 & 19.18 & 18.43 & 19.06 & 18.75 & -3.42 & -0.44 \\
\hline S. noctiflora & $9-12 \mathrm{C}$ & Yes & 20.49 & 20.57 & 20.53 & 19.16 & 19.31 & 19.23 & 20.55 & 20.25 & 20.40 & -0.09 & 1.17 \\
\hline S. noctiflora & $9-7 A$ & No & 23.64 & 23.67 & 23.65 & 20.07 & 20.26 & 20.16 & 20.71 & 20.17 & 20.44 & -3.21 & 0.27 \\
\hline S. noctiflora & $9-7 \mathrm{~A}$ & Yes & 21.43 & 21.38 & 21.41 & 20.63 & 20.73 & 20.68 & 21.07 & 20.86 & 20.96 & -0.47 & 0.28 \\
\hline S. noctiflora & $9 a-A 1$ & No & 27.27 & 27.08 & 27.18 & 22.23 & 21.88 & 22.05 & 21.89 & 21.83 & 21.86 & -5.41 & -0.19 \\
\hline S. noctiflora & $9 a-A 1$ & Yes & 21.95 & 21.89 & 21.92 & 20.71 & 20.99 & 20.85 & 22.11 & 21.78 & 21.95 & 0.00 & 1.10 \\
\hline S. noctiflora & 9A-B1 & No & 19.72 & 19.89 & 19.81 & 19.15 & 19.17 & 19.16 & 18.94 & 19.14 & 19.04 & -0.68 & -0.12 \\
\hline S. noctiflora & $9 \mathrm{~A}-\mathrm{B} 1$ & Yes & 20.42 & 21.05 & 20.73 & 19.05 & 20.04 & 19.55 & 20.65 & 20.60 & 20.62 & 0.21 & 1.08 \\
\hline S. noctiflora & $9 \mathrm{c}-\mathrm{A} 3$ & No & 24.74 & 24.45 & 24.60 & 20.89 & 20.88 & 20.89 & 20.64 & 20.78 & 20.71 & -4.03 & -0.18 \\
\hline S. noctiflora & $9 c-A 3$ & Yes & 21.94 & 22.06 & 22.00 & 20.93 & 21.07 & 21.00 & 22.60 & 22.50 & 22.55 & 0.61 & 1.55 \\
\hline
\end{tabular}




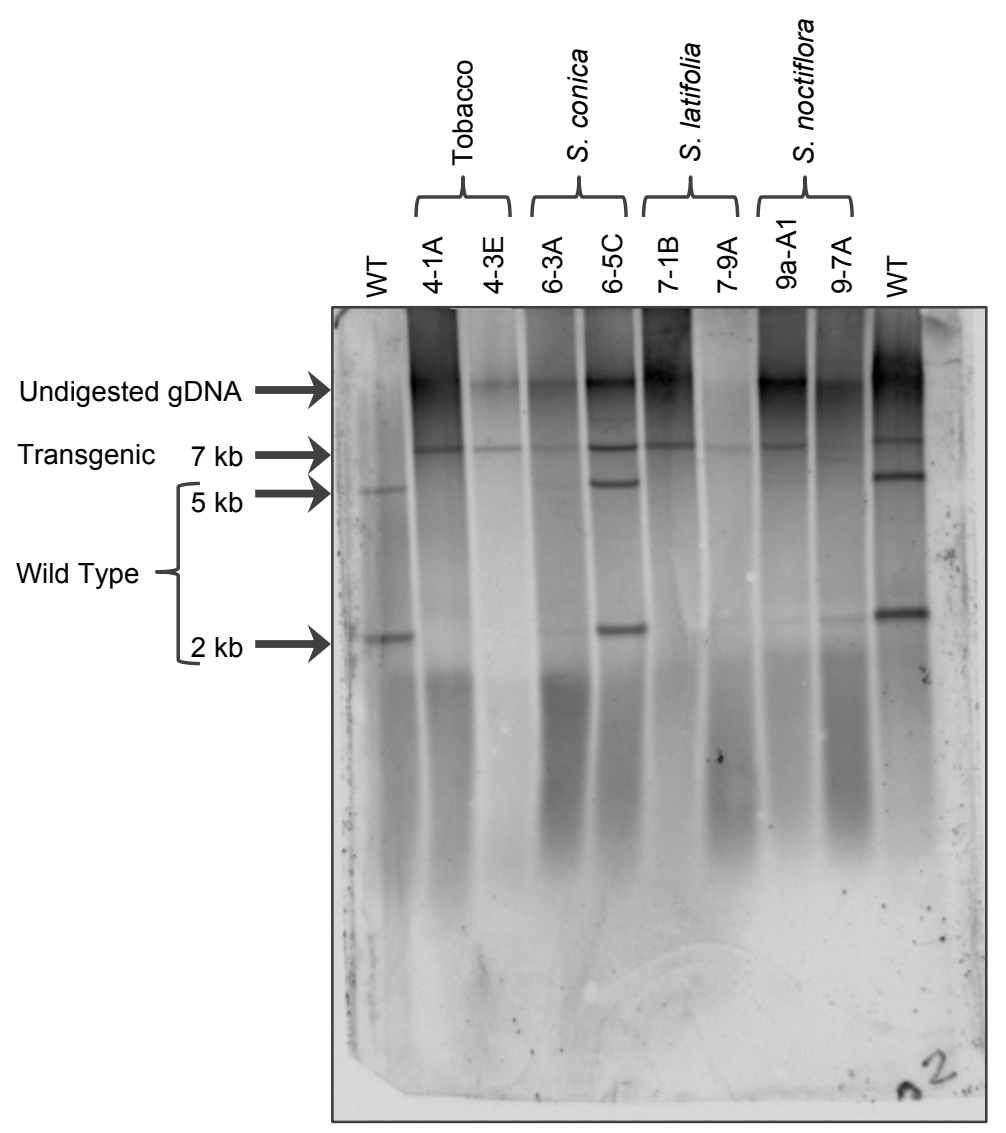

Figure S1. Southern blot analysis of select wild type and transgenic lines, confirming presence of the transgenic construct. 


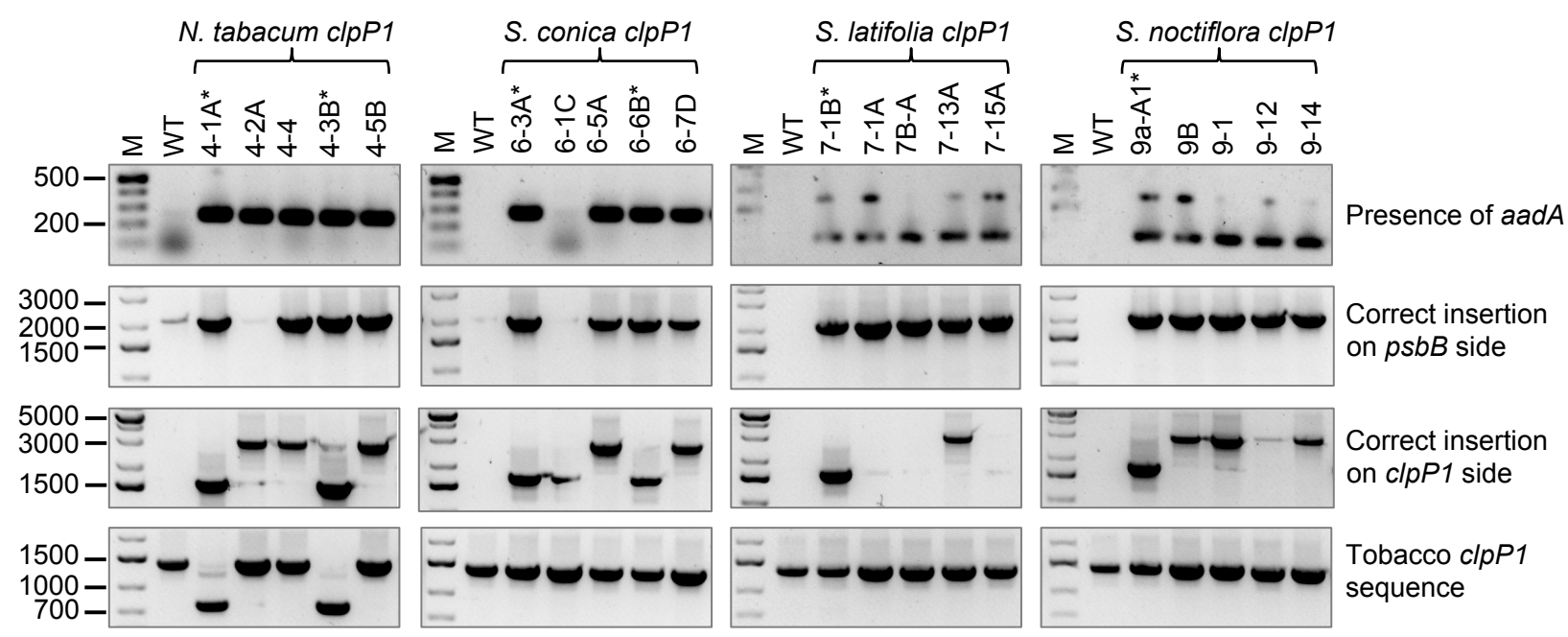

Figure S2. Examples of transgenic lines with improper insertions or internal recombination events. The lines marked with asterisks exhibit the expected product size for each of the four PCR markers (see Figure 3). 